\section{Nathalie Doury}

is general manager in charge of business development of AMC Europe, a fully owned subsidiary of one of the largest international cinema exhibition circuits, AMC Entertainment. A French national, she joined AMC in 1993 and supervises the company's expansion plans in Europe, where by the end of 2001 it will operate 12 multiplexes and 240 screens in Spain, Portugal, France, the $U K$ and Scandinavia.

Keywords:

cinema, multiplex, leisure, urban entertainment centre
Nathalie Doury General Manager AMC Europe SA,

62-64 Boulevard Péreire, 75017 Paris,

France

Tel: +33 (o) 142120292

Fax: +33 (o) 142120118

E-mail: ndoury@amctheatres.com

\section{Successfully integrating cinemas into retail and leisure complexes: An operator's perspective}

\author{
Nathalie Doury
}

Received: 15th September, 2000

\begin{abstract}
The expansion of cinemas in the European market continues. Today, no new shopping centre is being built without a leisure component, usually including a multiplex. Leisure-based centres have also emerged, first in the form of leisure parks, and now in the form of urban entertainment centres (UECs). But what is the formula - if there is one - to create successful leisure schemes for the decades to come? How will destination-based leisure and retail concepts cope with the forthcoming 'e-revolution'?

This paper is from the perspective of a multiplex operator. It focuses on basic guidelines to maximise the synergy between the cinema and the other components of the leisure mix, and to help replicate the urban experience in a constantly evolving environment.
\end{abstract}

\section{THE CONTEXT}

The leisure sector is evolving fast, under pressure of sociodemographic factors, but also driven by changes in urban structures, shifts in planning policies and the evolution of technology.

The ageing of the Western world's population will be a marked feature of the next decades, and the process has already started, with an increasing shift in purchasing power from the younger to the older. The baby-boomer generation is now in its $40 \mathrm{~s}$ or $50 \mathrm{~s}$, and senior citizens will be the fastest growing age group until 2010. In 1950 , the over- 65 s represented 9.4 per cent of the population of the EEC countries; they now account for 15.5 per cent and the figure is expected to grow to 20.7 per cent by 2020 . On the other hand, the under-15s, who represented nearly a quarter of the population in the early 1950s will barely account for 15 per cent in $2020{ }^{1}$

Although still dominated by 15-24-year-old customers, the leisure market therefore needs to target young to middle-aged adults and their parents.

The characteristics of the average household have also evolved, with two major changes: the traditional married couple with children is no longer the dominating model, and the percentage of working women has steadily increased since the Second World 


\section{Evolution in leisure locations}

\section{The third cinema revolution}

War. Between 1972 and 1994, the nuptiality rate in the EEC fell from 7.2 per cent to 5.1 per cent - a 29 per cent decrease - the number of divorces doubled and the number of children born outside wedlock soared from 5 per cent in the 1960s to 22 per cent at the end of the 20th century. Simultaneously, the number of working women increased by close to 50 per cent in Western Europe, to represent over one-third of the total workforce.

Older consumers are more sophisticated in their choices, and more demanding than the average teenager. They have a higher income and a wider choice available in terms of entertainment activities, both at home and when going out, than their parents. Inhouse entertainment, in particular, has been the dominating phenomenon of the post-war era, with the multiplication of television channels, VCR, DVDs, and now the Internet. Consumers are therefore dedicating a growing portion of their disposable income and their time to leisure pursuits. But this free time is fragmented, hence a somewhat paradoxical expectation of greater efficiency in the use of leisure time.

Leisure locations are also changing, following the fluctuation of urban structures. Traditionally located within city centres, where entire entertainment districts emerged over time, leisure, like retail in the 1970s, has moved out of town due to high land costs, the development of residential suburbs and the domination of the car as a mode of transportation.

Such locations have their advantages in terms of access and convenience, but the standard leisure park designers too often forgot that entertainment is not all about functionality, creating standardised boxes lost in an ocean of car parking. In three decades however, history has gone full circle, and the most recent trend is a return to the city and town centres, strongly encouraged, or forced, as the case may be, by planning and transport policies.

Following such trends, cinema, being one of the original art forms of the 20th century but also a specific kind of retailing, has already undergone its third revolution.

From the mid-1960s, the single-screen movie palaces that had ruled the cinema for half a century started to be replaced by 'multis', either multi-screen facilities created out of the carving out of the old theatres, or custom-built multiplexes. First introduced in the USA the typical multiplex featured six to 12 screens and, for the first time, offered customers a choice of films and viewing times. The multiplexes were typically located in regional malls or retail parks, and offered a somewhat standardised design with sloped auditorium floors, modern sound and projection systems, bars selling a variety of soft drinks and confectionery and a large carparking provision. Multiplexes fulfilled the needs of movie-going patrons for over 30 years, and fuelled an impressive growth both in attendance and revenue in most Western countries.

However, in the mid-1990s, a few major exhibitors, including AMC, undertook extensive surveys of their customers' expectations. 


\section{New generation multiplexes}

The conclusions were that although the basic requirements in terms of convenience were satisfied by the first generation of multiplexes, the research identified a clear demand for an even wider choice of films, a more sophisticated requirement with regards to technological quality (no doubt fuelled by a general increase in the quality level of cinemas, but also of its direct competitor, TV), a critical eye on design and decoration, and higher expectations in terms of customer service. This prompted a strategic decision by AMC, soon followed by its main competitors, to focus on the 'newgeneration' multiplexes, featuring from 14 to up to 30 screens, and offering the best in terms of comfort and technology. The so-called 'megaplexes' offer stadium-style stepped auditoria, high-quality seats with headrests and retractable armrests, wall-to-wall curved screens, digital sound, ample spectacularly designed and sometimes themed lobby and circulation space and a wider range of food and drinks on sale. In summary, these theatres combine the best of both worlds: the impressive architecture, glamour — sometimes luxury — and comfort of the cinemas of the 1950s, and the technological edge, wide choice of films and quality of service offered by the multiplexes of the 1980s. They now represent a substantial portion of the theatre portfolio of the large US exhibition chains (60 per cent of AMC's screens are now in megaplex format) and keep growing.

But offering the best facilities is not enough to satisfy the most demanding customers, who claim they can just as well watch a movie at home. One of the responses is the urban entertainment centre, or UEC.

\section{THE UEC AS A ONE-STOP LEISURE DESTINATION}

UECs combine a cinema anchor with a wide range of leisurerelated uses, aiming to create a one-stop entertainment destination of regional magnitude.

By offering a critical mass of activities in the same location, such centres provide an opportunity for customers to optimise the use of their leisure time and spend a night or an afternoon out with the family or a group of friends without a particular choice of activity in mind.

From the point of view of the operators and centre owners, the combination of different activities helps extend the catchment area and trading hours, increases the spend per visit, promotes repeat business and allows the sharing of infrastructure costs among several tenants. This is the reason why most of the major cinema exhibitors in the USA and Europe now favour such centres as their location of choice for the new-generation megaplexes, and get more involved from the onset - sometimes originating the projects themselves - in the definition of the tenant mix and the design of the schemes. This is certainly the case for AMC: all of their cinemas opened within the past three years have been integrated within UECs or, alternatively, within the expanding leisure sections of regional shopping centres. 


\section{The tenant mix}

\section{Cinema anchors}

\section{Compatible neighbours}

Compatibility and synergy drive the composition of the ideal tenant mix in UECs. Tenants should be compatible in terms of target demographic groups, frequency of use, image and operating hours. They should be synergetic in offering activities to perform in sequence - for instance, cinema and restaurant - activities which feed each other - health club and sports store - or activities which allow the family group to split - casino and FEC.

Typical tenants in UECs tend to fall within one of the following categories, the relative importance of which varies according to the markets, planning regulations and availability of operators.

New-generation multiplex cinemas usually play the role of the anchor, generating an ample customer flow (1.5 to 2.5 million patrons a year for a 16-20 screen, state-of-the art multiplex).

Cinema patrons tend to be younger, more educated and of higher socio-economic groups than the average population, at the same time being more prone to consumption of leisure, culture or technology-related goods.

In addition, although the average attendance per head of population to the cinema in Europe is two to three times a year, the portion of the population who do attend the cinema tend to go on a frequent basis - five to six times a year on average - going up to ten to 12 times among the 15-24 year-olds and students. Cinema patrons are therefore desirable customers for the other tenants of the UEC. An important factor will be how the multiplex schedules its sessions: AMC, for example, has always promoted staggered showtimes to ensure a smoother, consistent flow of patrons for its neighbours: shows starting all within a ten-minute interval might create artificial peaks, thus generating congestion and saturation of the circulation spaces and car parking.

The second category is restaurants and bars. Consumption of food away from home - eating out - has increased significantly over the last decade, while sales in food stores have decreased, a phenomenon linked to a variety of societal factors, such as the decline of the traditional family model. In addition, the synergy between cinema and food and beverage is strong. Surveys show that over two thirds of cinema patrons are likely to seek a meal or a drink before or after the film and 'spill over' to adjacent restaurants and bars. This generates the requirement for a wide range of food to be offered in UECs, from fast food and sandwich counters to full service restaurants, from ethnic food to themed bars, from international chains to local mom-and-pop operations.

The name of the game here is diversity: of pricing, of style of cuisine, of speed and quality of service, to cater for a variety of age groups, lifestyles and incomes. The food offered is usually the weakness of most traditional leisure parks, limited to the same fast food/American-style diners, which appeal to teenagers but will actually repel the adult portion of the audience.

Third come other leisure uses, either image related like largeformat film attractions, such as Imax theatres, or more traditional 
The 'experience' component

The retail content

\section{Make it exciting}

venues, such as bowling, games, family entertainment centres, casinos, music bars, comedy clubs and nightclubs. New technologybased formats are now emerging, either offering 'virtual reality' experiences, or proposing educative entertainment through a variety of media, barbarously termed 'edutainment' in specialised lingo. These facilities will usually appeal to the younger portion of the audience.

Sports-related activities, such as artificial snow slopes or glorified swimming pools, are also often found in UECs, as well as health and fitness centres. Although not directly synergetic with the other activities - chances are no one will visit the cinema after two hours of strenuous physical exercise - sport-based activities reinforce the daytime attraction of the entertainment centres, while appealing to desirable target demographic groups. They also reinforce the 'experience' component of the venue, which will become a critical factor in the 'age of virtuality' - as emphasised in the conclusion of this paper.

The mix can be successfully completed with retail, although not just any type of retail. Purely convenience shopping, including food, does not hold any synergy with entertainment. However, culture and sport-related retail concepts such as mega-bookstores, record and video stores, sports clothing or apparel, or hi-fi/computer stores perform well in the context of UECs. This can be extended to the so-called 'lifestyle' retailers such as The Gap, NikeTown or the Nature Company, which capitalise on impulse purchase, develop attractive and spectacular store formats and target a population likely to be found in such centres.

Finally, no UEC is to be complete without a lively animation policy, using live music, street theatre, carrousels, fashion shows, waterworks or light shows as an integral part of the mix, and as a way to renew itself constantly. Such attractions might increase the service charge, but can also become alternative sources of revenue through branding or sponsoring.

As a conclusion to this 'tenant mix' section, a word on the letting strategy: developers and investors should take a flexible view in the choice of operators and beware of a strictly covenant-led approach. Selecting only large international brands and major leisure chains is certainly preferable from a financial risk point of view, but will do little to differentiate the centre from its competition, or the shopping centre next door. On the other hand, a creative tenant mix, involving well known names as well as local or independent talented operators, will reinforce the attraction of the scheme, giving it a unique as well as a local touch, and ensuring its durability.

\section{THE UEC AS AN URBAN EXPERIENCE}

The location, planning and design of such centres will aim at maximising the critical mass effect and synergy between the tenants, but will also need to follow more subtle cues. The biggest challenge 
Location, location, location

\section{Re-inventing the city centre}

faced by the UECs is to create a lively and exciting environment for their visitors.

The choice of location will follow criteria used by any large retail project: ample catchment area with the right demographic characteristics (here, a large spend on leisure is the most important factor), good car and public transportation access, visibility and sufficient available land. The eternal debate between out of town or city centre is not the major issue here. Out-of-town locations will offer better car access and lower land costs, but will face planning restrictions and a difficult challenge differentiating from the nondescript mass of suburban developments; in-town projects will have to tackle more acute technical constraints and higher costs, but will benefit from better public transport service and an already vibrant environment. In that regard, urban regeneration projects, or reclamation of former industrial sites, warehouses or factories, often located close to the centre of towns can be a major opportunity for UEC development.

The planning will seek to balance and optimise the flows generated by the various tenants while taking into account their technical requirements (height, structure, etc), their operating constraints (car-parking needs, trading hours, deliveries and servicing requirements) and the fine balance between the identity of each venue and its integration into the whole.

However, beyond pure functionality, designers must not forget they are creating a place for people to go out to - as opposed to staying at home - and be entertained, a place to hang around in, spend time and interact with other people. For most Europeans, this place is in fact the city centre, whether real, remembered or imagined. Europeans have a strong cultural - and almost affective - link with the urban heart of the city. Recreating this delicate alchemy out of town, or in a formerly industrial environment, is indeed a difficult task, and it is where a lot of retail or leisure centres have failed, but it has also been the guideline used in most successful UECs. Beyond the historical dimension and the combination of uses - residential, business, shopping and leisure — the city is made of buildings and public spaces, giving a theatrical setting to human interactions.

First, cars need to be kept at a distance: nothing is more adverse to strolling around than having constantly to keep one's steps and one's children out of the range of speeding automobiles - and a car park is not the most attractive meeting place, especially at night.

The introduction of urban structures and forms, especially through the creation of quality public space, plazas, promenades, arcades, terraces and, in the case of covered centres, malls and atriums, will also be fundamental in creating a lively sense of place. Needless to say, such public spaces, as well as the car parking, will have to be impeccably maintained, cleaned, lighted and offer a sense of safety, especially to female patrons. 
Three categories of UECS
Finally, the architecture should introduce a spectacular dimension, emphasising focal points and avoiding uniformity in the integration of individual tenants. Signage, lighting and light design features should be an important element of the mix, allowing the centres to evolve and transform themselves as time passes and the tastes of the public change.

Using this approach, most UECs can be classified into one (or a combination) of the following categories: the street or plaza schemes - both more adapted to out-of-town locations and sunny climates - or the urban vertical schemes.

Take for example Universal City Walk, the grandfather of all UECs, built on the former Universal Studios plot in Los Angeles. The 1,500 foot long street, according to its designer, the American architect Jon Jerde 'pays homage to Los Angeles'. Jerde adds:

'the theme of Los Angeles is that there is no theme. That's what makes the city so eclectic. [...] The architects have looked to real streets for design cues, encouraging each tenant to develop its visual identity whilst master-planning the scheme around a relatively narrow street bordered by two-storey buildings and layering urban elements, such as bridges, or arcades to break the uniformity of the perspective."2

The Spectrum at Irvine, California, featuring an Edwards 20-screen multiplex is a plaza scheme, built around a large pedestrian space facing the cinema.

The Block, an 800,000 square foot retail and leisure scheme in Orange, California, is a street/plaza scheme, made up of two 1,200 foot long pedestrian promenades, the Boulevard (retail oriented) and the Strip (wilder, leisure related), connected by a large plaza embellished with fountains and facing the 30-screen AMC multiplex. The Block's motto is flexibility and evolution. As Jerry Engen of the Mills Corporation puts it:

'the Block needs to stay hip and cool, constantly evolving in appearance to suit the fickle fashion whims of a restless culture. We plan to apply fresh colours and signage to reinvent continually the Block's look and aura. We can change as rapidly as the culture changes. 3

In Europe, the Heron City leisure schemes in Madrid and Barcelona and the Festival Park project in Palma de Majorca are directly inspired by such developments.

In the USA again, the rebuilding of the historical Empire theatre on New York's 42nd Street is a good example of an urban vertical UEC (it actually does not get much more urban, or more vertical!). Featuring a spectacular, partly re-used frontage, the building steps back in its higher levels in proper skyscraper style, creating outside terraces overlooking busy streets and, occasionally, the Hudson 
river. The 335,000 square foot scheme, including a 145,000 square foot 25-screen AMC cinema, a Madame Tussaud wax museum, the Manhattan flagship of HMV records and a wide range of restaurants and bars, is developed on six floors linked by 14 escalators. An operating nightmare, but a true New York destination. In the UK, the UCI-anchored Printworks, the Great Northern Warehouse in Manchester and the Broadway Plaza scheme in Birmingham (both featuring an AMC Megaplex) re-use existing buildings, creating attractive interior and exterior space within multi-storey developments.

\section{UECS AND THE DOT COM REVOLUTION}

'The Internet is forever changing the way we shop, but also the way we interact with others or entertain ourselves.' This widely heard statement is true, but it is not the whole truth, and here lies one of the strengths of the UECs in tomorrow's virtual world.

Fact: people will be making their day-to-day, boring purchases on the Internet and will look for home delivery or convenient pickup points. They will also use the Web to compare prices, book airline tickets and balance their accounts — virtual shopping.

Fact: people will have access to an unlimited choice of music, videos and films on demand, available on their computer thanks to a simple click on the mouse (and a valid credit card number...) virtual entertainment.

Fact: people will more and more converse with their friends over the Net, through e-mail, video conferences and net-cams - virtual social life?

Fact: UECs can make great use of the opportunities created by the new technologies, in terms of both service (advance bookings, information on programmes) and marketing (advertising, special offers, customer surveys).

The Internet provides speed (time saved for leisure), choice and convenience, but well-planned UECs satisfy other needs. They offer a 'real' experience as opposed to a virtual one. They allow people to meet, watch and interact with other people, to experience physical sensations - no virtual meals or swimming pools in view yet - to try on products, to hear live music, or watch films on a larger than life - and much larger than a computer monitor screen, with 600 other fellow spectators... They offer excitement and a sense of community and, as such, are best equipped to survive the e-revolution, as cinemas survived the advent of TV and video. ${ }^{4}$

\section{References}

1. Bardet, J.P. and Dupâquier, J. (1999) Histoire des populations de l'Europe, Fayard.

2. Shopping Center World (1994) 'Universal Citywalk', February.

3. Urban Land (1999) 'Revved up', February.

4. Urban Land (2000) 'The experience economy', February. 